\title{
Comparación del Sistema de Incubación de Etapa Única vs Etapa Múltiple sobre los Parámetros Productivos de Huevos de Reproductoras de Carne de Tres Edades
}

\author{
Comparison of Single Stage vs Multi Stage Incubation Systems on Performance \\ of Hatching Eggs of Broiler Breeders of Three Ages
}

Daniel Maekawa M. ${ }^{1}$, Pablo Reyna S. ${ }^{2}$, Mónica Alba C. ${ }^{1}$, Eloy Gonzales G. ${ }^{3}$

\section{Resumen}

El presente estudio tuvo como objetivo comparar los resultados productivos entre los sistemas de incubación de etapa única vs etapa múltiple de huevos procedentes de reproductoras de carne de tres grupos de edades. Se utilizaron 21878026 huevos incubables de reproductoras de carne de la línea Cobb 500 (emplume lento) de tres rangos de edades: lotes de madres jóvenes (24 a 35 semanas), adultas ( 36 a 50 semanas) y viejas (51 a 63 semanas) por un periodo de un año. Se encontró una menor mortalidad embrionaria total en el sistema de etapa única en comparación al sistema de etapa múltiple ( $\mathrm{p}<0.05)$, tanto en lotes de jóvenes (9.55 vs $10.49 \%)$, adultas ( 7.06 vs $9.62 \%)$ y viejas $(8.31$ vs $12.55 \%$ ), así como una mayor incubabilidad y nacimiento total en el sistema de etapa única en comparación al sistema de etapa múltiple en los tres lotes de edades $(\mathrm{p}<0.05)$. Asimismo, se encontró un mejor aprovechamiento de los lotes de reproductoras viejas en el sistema de incubación de etapa única.

Palabras clave: mortalidad embrionaria, fertilidad, incubabilidad, etapa única, etapa múltiple

\section{Abstract}

The aim of the present study was to compare the productive performance of single stage versus multiple stage incubation in eggs of broiler breeders of three age groups. In the incubation process was used 21878026 eggs from Cobb 500 broiler breeders (slow

\footnotetext{
${ }^{1}$ San Fernando SA, Lima

${ }^{2}$ Laboratorio de Patología Aviar, Facultad de Medicina Veterinaria, Universidad Nacional Mayor de San Marcos, Lima, Peru

${ }^{3}$ Estación Experimental del Centro de Investigación IVITA, El Mantaro, Universidad Nacional Mayor de San Marcos, Huancayo, Perú

${ }^{4}$ E-mail: daniel1703@hotmail.com
}

Recibido: 7 de abril de 2014

Aceptado para publicación: 26 de agosto de 2014 
feather) grouped in three age categories: young ( 24 to 35 weeks), adults ( 36 to 50 weeks), and old (51 to 63 weeks) for a period of one year. The results showed lower total embryonic mortality in the single stage as compared to the multi stage incubation system $(\mathrm{p}<0.05)$, both in the young (9.55 vs $10.49 \%)$, adult (7.06 vs $9.62 \%)$ and old breeders (8.31 vs $12.55 \%$ ) as well as higher total hatchability and hatchability of fertile eggs in the single stage incubation system in the three age groups $(\mathrm{p}<0.05)$. In addition, it was found a better utilization of the older breeders under the single stage incubation system.

Key words: embryonic mortality, fertility, hatchability, single stage, multiple stage

\section{INTRODUCCIÓN}

El mejoramiento genético en la industria avícola ha dado como resultado una enorme diversidad de líneas genéticas, en muchas de las cuales los huevos requieren condiciones específicas de incubación. El metabolismo del embrión está cambiando como resultado de la selección por características de producción. Actualmente los embriones crecen más rápido, tienen un intercambio más acelerado de gases y generan mayor calor durante el proceso de incubación (Meijerhof, 2011).

La planta de incubación es un componente esencial en la cadena de producción avícola, que junto con todo lo relacionado al huevo, son los que determinan la calidad y vitalidad del pollito de un día, el cual, a su vez, es el factor que en último término determina la calidad y el desempeño del producto final (Boerjan, 2004).

Dentro de los sistemas de incubación actuales, la incubación tradicional en etapas múltiples ha dejado de ser económicamente eficiente, porque las temperaturas del embrión son demasiado bajas o demasiado altas (Hulet, 2007), haciendo difícil determinar la temperatura de la incubadora de manera de asegurar la correcta temperatura de la cáscara del huevo para cada estado embrionario (Boerjan, 2004). En las incubadoras de carga múltiple, hay embriones de distintas edades, siendo común encontrar sectores con diferentes temperaturas (Navarro, 2003).

Otra de las desventajas en las incubadoras de etapa múltiple es la dificultad que presentan para efectuar una limpieza y desinfección completa en su interior, a menos que la unidad se encuentre vacía y en rotación para limpieza y mantenimiento (Bennett, 2010). En general, las condiciones por debajo de las ideales de las incubadoras de cargas múltiples resultan en menor porcentaje de eclosión y con pollitos de menor calidad (Hulet, 2007).

De este modo, la industria avícola se está inclinando hacia la incubación de etapa única (Hemeryck, 2009), donde la máquina se llena una sola vez con huevos del mismo tipo o lote de reproductoras, de manera que se trabaje con huevos en la misma fase embrionaria, creando las condiciones óptimas de temperatura, humedad y ventilación para cada fase del desarrollo embrionario, obteniéndose mejoras en los parámetros de incubación. Las incubadoras de etapa única, basadas en el concepto «todo-dentro todofuera», posibilitan, además, una mayor bioseguridad y mejor limpieza de las máquinas (Bennett, 2010).

El presente estudio buscó comparar los sistemas de incubación de etapa única vs etapa múltiple, y su impacto en los resultados productivos del proceso de incubación en lotes de reproductoras de diferentes edades. 
Cuadro 1. Resumen de lotes evaluados y total de huevos incubados y analizados, de acuerdo al sistema de incubación y edad del lote

\begin{tabular}{lccccc}
\hline $\begin{array}{l}\text { Sistema de } \\
\text { Incubación }\end{array}$ & $\begin{array}{c}\text { Lote } \\
\left(\text { edad de las }^{\text {madres }} \text { ) }\right.\end{array}$ & $\begin{array}{c}\text { Lotes } \\
(\mathrm{n})\end{array}$ & $\begin{array}{c}\text { Huevos incubados } \\
(\mathrm{n})\end{array}$ & \multicolumn{2}{c}{ Embriodiagnosis } \\
\hline Múltiple & Joven & 203 & $5^{\prime} 694,432$ & 404,928 & 7.11 \\
& Adulta & 165 & $3^{\prime} 092,124$ & 289,152 & 9.35 \\
& Vieja & 112 & $2^{\prime} 299,738$ & 183,168 & 7.96 \\
\multirow{2}{*}{ Única } & Joven & 203 & $4^{\prime} 163,176$ & 261,450 & 6.28 \\
& Adulta & 165 & $3^{\prime} 801,518$ & 290,700 & 7.65 \\
& Vieja & 112 & $2^{\prime} 827,038$ & 343,800 & 12.16 \\
\hline \multicolumn{2}{l}{ Total } & 960 & $21^{\prime} 878,026$ & $1^{\prime} 773,198$ & 8.10 \\
\hline${ }^{1}$ Madres jóvenes (25-35 semanas), adultas (36-50 semanas) y viejas (51-63 semanas) &
\end{tabular}

\section{MATERIALES Y Métodos}

\section{Lugar de Estudio y Equipo}

El estudio se realizó en la empresa San Fernando SA, Lima, Perú, entre enero y diciembre de 2011, donde se evaluó la capacidad y eficiencia de incubación de huevos utilizando equipos de etapa única y múltiple.

Los equipos utilizados para la etapa única fueron la incubadora S-Line (ASPlus 24S), con capacidad para 115200 huevos (768 bandejas de 150 huevos c/u), y la nacedora S-Line (ASPlus 8H), con capacidad para 38400 huevos (256 bandejas de 150 huevos c/u), ambas de la empresa Petersime (Bélgica). Los equipos utilizados para la etapa múltiple fueron la incubadora CMg 125HT, con capacidad para 124416 huevos (1296 bandejas de 96 huevos c/u), y la nacedora CMg $125 \mathrm{HT}$, con capacidad para 20736 huevos (216 bandejas de 96 huevos c/u), ambas de la empresa CASP (Brasil).

\section{Operaciones de Manejo}

Se utilizaron huevos incubables provenientes de reproductoras de carne de la línea Cobb 500 (emplume lento). Los huevos fueron clasificados de acuerdo a la edad de las reproductoras en madres jóvenes (25-35 semanas), madres adultas (36-50 semanas) y madres viejas (51-63 semanas). Cada uno de estos lotes se incubó en forma simultánea en los dos sistemas (Cuadro 1).

En la planta de incubación, los huevos fueron almacenados de 3 a 6 días en cámaras de frío entre 17 a $20{ }^{\circ} \mathrm{C}$ y con una humedad relativa de 70 a $85 \%$. Luego del embandejado, los huevos fueron colocados en los coches porta-bandejas para su precalentamiento por 6 horas. Asimismo, dos bandejas de huevos por lote de reproductora y máquina incubadora fueron pesadas para determinar la pérdida de peso, la cual estuvo entre 10 a 12\%. En el proceso de incubación se programó el volteo de huevos cada hora, para evitar que el embrión se pegue a las membranas de la cáscara. 
Cuadro 2. Perfiles de incubación según el sistema de incubación en etapa única o múltiple

\begin{tabular}{llcc}
\hline \multirow{2}{*}{ Parámetros } & \multicolumn{2}{c}{ Sistema de incubación } \\
\cline { 3 - 4 } & & Etapa múltiple & Etapa única \\
\hline Pre-calentamiento $\left({ }^{\circ} \mathrm{C}\right)$ & $24-27$ & 27 \\
\multirow{2}{*}{ Incubadora } & Temperatura inicial $\left({ }^{\circ} \mathrm{C}\right)$ & 37.5 & 38.0 \\
& Temperatura final $\left({ }^{\circ} \mathrm{C}\right)$ & 37.5 & 37.0 \\
& Humedad $(\%)$ & 82 & 85 \\
\multirow{3}{*}{ Nacedoras } & & 36.9 & 36.7 \\
& Temperatura inicial $\left({ }^{\circ} \mathrm{C}\right)$ & 36.9 & 36.1 \\
& Temperatura final $\left({ }^{\circ} \mathrm{C}\right)$ & 84 & 83 \\
\hline
\end{tabular}

La fertilidad se evaluó mediante la prueba de ovoscopía a los 10 días de incubación (Bongalhardo, 2012), a fin de separar los huevos claros, que no han tenido desarrollo alguno, diferenciando de esta manera los huevos infértiles con los de mortalidad temprana.

La mortalidad embrionaria se estimó mediante la técnica de embriodiagnosis, definida como el conteo de la mortalidad embrionaria a partir de la apertura de los huevos que quedaron sin eclosionar en las bandejas de nacedoras (Plano y Di Matteo, 2001). Para esto, se escogieron tres bandejas de huevos por lote de reproductoras y por máquina incubadora en el caso de las incubadoras de etapa única (Nilipour, 2009), siendo estas de la parte superior, parte media y parte inferior de las máquinas. En el caso de las incubadoras de etapa múltiple se utilizaron seis bandejas debido a su menor capacidad.

Los perfiles de incubación utilizados en la planta de incubación se muestran en el Cuadro 2.

\section{Parámetros de Evaluación}

Los resultados obtenidos con la embriodiagnosis fueron ponderados al total de huevos incubados de cada lote según Pla- no y Di Matteo (2001). Se determinó la mortalidad embrionaria temprana ( 1 a 7 días de incubación), intermedia (8 a 14 días de incubación), y tardía (15 a 21 días de incubación), y mortalidad total. Asimismo, se determinó la frecuencia porcentual de huevos fértiles, picados no nacidos, rajados y contaminados.

Se determinó la incubabilidad (\%), así como la tasa de nacimientos, tanto en forma total, como de primera y de descarte. Para esto, se emplearon las siguientes fórmulas:

- Incubabilidad $(\%)=($ Nacimiento total $/$ Fertilidad) x 100

- Nacimiento total $(\%)=($ Total de pollitos nacidos / Total de huevos incubados) $\mathrm{x}$ 100

- Nacimiento de primera $(\%)=($ Pollitos de primera / Total de huevos incubados) $\mathrm{x} 100$

- Descarte $(\%)=($ Pollitos de descarte $/$ Total de huevos incubados) x 100

\section{Análisis Estadístico}

Los datos fueron analizados mediante un análisis de varianza de dos vías, con diseño factorial 2 x 3 (dos sistemas de incubación, tres edades de reproductoras), teniendo como 
Cuadro 3. Mortalidad embrionaria en huevos de aves reproductoras de carne, según el sistema de incubación y la edad del lote ${ }^{1}$

\begin{tabular}{|c|c|c|c|c|c|c|c|}
\hline \multirow[b]{2}{*}{ Tratamientos } & \multicolumn{3}{|c|}{ Mortalidad } & \multicolumn{3}{|c|}{ Huevos } & \multirow[b]{2}{*}{$\begin{array}{c}\text { Mort. } \\
\text { total } \\
(\%)\end{array}$} \\
\hline & $\begin{array}{c}\text { Tem- } \\
\text { prana } \\
(\%)\end{array}$ & $\begin{array}{l}\text { Inter- } \\
\text { media } \\
(\%)\end{array}$ & $\begin{array}{c}\text { Tardía } \\
(\%)\end{array}$ & $\begin{array}{c}\text { Picado } \\
\text { no } \\
\text { nacidos } \\
(\%)\end{array}$ & $\begin{array}{l}\text { Contami- } \\
\text { nados } \\
(\%)\end{array}$ & $\begin{array}{c}\text { Rajados } \\
(\%)\end{array}$ & \\
\hline \multicolumn{8}{|c|}{ Sistema de incubación } \\
\hline Etapa múltiple & $5.58^{\mathrm{a}}$ & $0.36^{\mathrm{a}}$ & $3.72^{\mathrm{a}}$ & $0.66^{\mathrm{b}}$ & $0.14^{\mathrm{a}}$ & $0.45^{\mathrm{a}}$ & $10.91^{\mathrm{a}}$ \\
\hline Etapa única & $4.22^{\mathrm{b}}$ & $0.29^{\mathrm{b}}$ & $2.78^{\mathrm{b}}$ & $0.95^{\mathrm{a}}$ & $0.06^{\mathrm{b}}$ & $0.01^{\mathrm{b}}$ & $8.31^{\mathrm{b}}$ \\
\hline \multicolumn{8}{|l|}{ Edad del lote } \\
\hline Joven & $5.56^{\mathrm{a}}$ & $0.32^{\mathrm{a}}$ & $3.07^{\mathrm{b}}$ & $0.92^{\mathrm{a}}$ & $0.07^{\mathrm{b}}$ & $0.08^{\mathrm{c}}$ & $10.02^{\mathrm{a}}$ \\
\hline Adulto & $3.99^{c}$ & $0.32^{\mathrm{a}}$ & $2.96^{\mathrm{b}}$ & $0.71^{\mathrm{b}}$ & $0.11^{\mathrm{a}}$ & $0.24^{\mathrm{b}}$ & $8.33^{\mathrm{b}}$ \\
\hline Viejo & $5.14^{\mathrm{b}}$ & $0.33^{\mathrm{a}}$ & $3.72^{\mathrm{a}}$ & $0.77^{\mathrm{b}}$ & $0.12^{\mathrm{a}}$ & $0.35^{\mathrm{a}}$ & $10.43^{\mathrm{a}}$ \\
\hline \multicolumn{8}{|l|}{ Incubación x Edad } \\
\hline Múltiple x Joven & 6.21 & 0.32 & 3.01 & 0.69 & 0.10 & 0.16 & 10.49 \\
\hline Múltiple x Adulto & 4.58 & 0.36 & 3.43 & 0.62 & 0.16 & 0.47 & 9.62 \\
\hline Múltiple x Viejo & 5.93 & 0.40 & 4.71 & 0.66 & 0.15 & 0.70 & 12.55 \\
\hline Única x Joven & 4.92 & 0.32 & 3.12 & 1.15 & 0.03 & 0.01 & 9.55 \\
\hline Única x Adulto & 3.40 & 0.28 & 2.50 & 0.80 & 0.07 & 0.01 & 7.06 \\
\hline Única x Viejo & 4.35 & 0.26 & 2.73 & 0.88 & 0.08 & 0.01 & 8.31 \\
\hline \multicolumn{8}{|l|}{ Probabilidad } \\
\hline Sist. incubación & 0.00 & 0.00 & 0.00 & 0.00 & 0.00 & 0.00 & 0.00 \\
\hline Edad del lote & 0.00 & 0.87 & 0.00 & 0.00 & 0.00 & 0.00 & 0.00 \\
\hline Incub. $x$ edad & 0.25 & 0.00 & 0.00 & 0.00 & 0.46 & 0.00 & 0.00 \\
\hline
\end{tabular}

a,b,c Superíndices diferentes dentro de columnas y tratamientos indican diferencia estadística $(p<0.05)$

${ }^{1}$ Madres jóvenes (25-35 semanas), adultas (36-50 semanas) y viejas (51-63 semanas)

variables dependientes la mortalidad embrionaria (total, temprana, intermedia, tardía), huevos picados no nacidos, contaminados y rajados, fertilidad, incubabilidad y nacimientos (total, primera y descarte).
Las comparaciones múltiples para cada factor se realizaron mediante la prueba de diferencia mínima significativa (DMS), empleando el paquete estadístico SPSS v. 19. 
Cuadro 4. Nacimientos, incubabilidad y fertilidad en huevos de aves reproductoras de carne por sistema de incubación y edad del lote ${ }^{1}$

\begin{tabular}{|c|c|c|c|c|c|}
\hline \multirow[b]{2}{*}{ Tratamientos } & \multicolumn{3}{|c|}{ Nacimiento } & \multirow{2}{*}{$\begin{array}{c}\text { Incubabilidad } \\
(\%)\end{array}$} & \multirow{2}{*}{$\begin{array}{l}\text { Fertilidad } \\
\quad(\%)\end{array}$} \\
\hline & $\begin{array}{c}\text { Primera } \\
(\%)\end{array}$ & $\begin{array}{c}\text { Descarte } \\
(\%)\end{array}$ & $\begin{array}{l}\text { Total } \\
(\%)\end{array}$ & & \\
\hline \multicolumn{6}{|c|}{ Sistema de incubación } \\
\hline Etapa múltiple & $80.00^{\mathrm{b}}$ & $2.18^{\mathrm{a}}$ & $82.17^{\mathrm{b}}$ & $88.31^{\mathrm{b}}$ & $92.93^{\mathrm{a}}$ \\
\hline Etapa única & $82.23^{\mathrm{a}}$ & $2.15^{\mathrm{a}}$ & $84.38^{\mathrm{a}}$ & $91.07^{\mathrm{a}}$ & $92.62^{\mathrm{a}}$ \\
\hline \multicolumn{6}{|l|}{ Edad del lote } \\
\hline Joven & $84.05^{\mathrm{b}}$ & $1.93^{\mathrm{b}}$ & $85.98^{\mathrm{b}}$ & $89.57^{\mathrm{b}}$ & $95.95^{\mathrm{a}}$ \\
\hline Adulto & $85.63^{\mathrm{a}}$ & $1.99^{\mathrm{b}}$ & $87.62^{\mathrm{a}}$ & $91.42^{\mathrm{a}}$ & $95.83^{\mathrm{a}}$ \\
\hline Viejo & $73.66^{\mathrm{c}}$ & $2.57^{\mathrm{a}}$ & $76.23^{\mathrm{c}}$ & $88.08^{\mathrm{c}}$ & $86.54^{\mathrm{b}}$ \\
\hline \multicolumn{6}{|l|}{ Incubación x edad } \\
\hline Múltiple x joven & 83.81 & 1.98 & 85.78 & 89.15 & 96.19 \\
\hline Múltiple $\mathrm{x}$ adulto & 84.59 & 1.96 & 86.55 & 90.14 & 96.00 \\
\hline Múltiple x viejo & 71.60 & 2.59 & 74.19 & 85.65 & 86.60 \\
\hline Única $\mathrm{x}$ joven & 84.30 & 1.88 & 86.18 & 90.00 & 95.72 \\
\hline Única $\mathrm{x}$ adulto & 86.66 & 2.02 & 88.68 & 92.70 & 95.66 \\
\hline Única $\mathrm{x}$ viejo & 75.72 & 2.55 & 78.27 & 90.52 & 86.49 \\
\hline \multicolumn{6}{|l|}{ Probabilidad } \\
\hline Sist. incubación & 0.00 & 0.60 & 0.00 & 0.00 & 0.13 \\
\hline Edad del lote & 0.00 & 0.00 & 0.00 & 0.00 & 0.00 \\
\hline Incub. x edad & 0.00 & 0.31 & 0.00 & 0.00 & 0.78 \\
\hline
\end{tabular}

\section{Resultados}

El sistema de incubación mostró mejores resultados en el sistema de incubación de etapa única en términos de mortalidad embrionaria total, así como en mortalidad embrionaria temprana, intermedia y tardía, y en el porcentaje de huevos contaminados y rajados $(\mathrm{p}<0.05)$. Por otro lado, en la frecuencia de huevos picados no nacidos se encon- traron mejores resultados para el sistema de incubación de etapa múltiple. Asimismo, la edad del lote de reproductoras afectó significativamente las variables de mortalidad $(\mathrm{p}<0.05)$, con excepción de la mortalidad intermedia (Cuadro 3).

La mayor mortalidad embrionaria ocurrió durante la primera semana de incubación, intermedia durante la tercera semana y menor en la segunda semana. 
Se observó una significativa interacción entre el sistema de incubación y la edad del lote sobre la mortalidad embrionaria intermedia, tardía y total. Estas diferencias entre sistemas de incubación fueron mayores para el grupo de reproductoras viejas y menores en el lote joven. Un comportamiento similar se observó en el caso de los huevos rajados (Cuadro 3). Por otro lado, el sistema de incubación sobre la frecuencia de huevos picados no nacidos causó un mayor efecto en los lotes de madres jóvenes, en tanto que no hubo diferencias entre los otros dos lotes (Cuadro 3).

No se encontró interacción significativa por efecto del sistema de incubación y la edad del lote para la mortalidad embrionaria temprana y para la frecuencia de huevos contaminados, observándose diferencias similares entre ambos sistemas de incubación para todas las edades (Cuadro 3).

El sistema de incubación tuvo un efecto significativo sobre el porcentaje total de nacimientos y el de primera, siendo mayor en el sistema de incubación de etapa única. Por otro lado, no hubo diferencia significativa en la frecuencia de descarte por efecto del sistema de incubación (Cuadro 4).

La edad del lote de reproductoras afectó significativamente el porcentaje total de nacimientos y de primera, observándose mayores nacimientos en el lote de madres adultas y menores en el lote de madres viejas $(p<0.05)$. La interacción sistema de incubación y edad del lote fue significativa en el nacimiento total y de primera, habiendo menores diferencias entre los lotes de madres jóvenes, intermedio entre los lotes adultos y mayores entre los lotes viejos (Cuadro 4). Por otro lado, no se observó una interacción significativa entre el sistema de incubación y la edad del lote de reproductoras sobre la tasa de descarte (Cuadro 4).

El sistema de incubación de etapa única presentó mejores resultados de incubabilidad que el sistema múltiple $(\mathrm{p}<0.05)$.
Asimismo, la tasa de incubabilidad fue mayor en el lote de madres adultas, siendo menor en el lote de madres viejas $(\mathrm{p}<0.05)$. La interacción sistema de incubación y edad del lote fue significativa, observándose una menor diferencia entre sistemas de incubación en el lote joven, intermedio en el lote adulto y mayor en el lote viejo (Cuadro 4).

El porcentaje de huevos fértiles fue similar en ambos grupos de incubación; sin embargo, se observó una mayor fertilidad en los huevos procedentes de reproductoras jóvenes y adultas en comparación a las reproductoras viejas (Cuadro 4). No se encontró interacción significativa entre el sistema de incubación y la edad del lote sobre la fertilidad.

\section{Discusión}

En el sistema de etapa múltiple se presentó la mayor mortalidad embrionaria intermedia y tardía en el lote de madres viejas (5.71\%), debido a que en este sistema es imposible ajustar la temperatura de la máquina para cada etapa embrionaria (Hulet et al., 2007), produciéndose un sobrecalentamiento del embrión a partir de los 9 días de incubación (Lourens et al., 2007). Además, los huevos de reproductoras de 51 a 63 semanas de edad tienen huevos de mayor tamaño, y que producen mayor calor embrionario (Meijerhof y Van Beek, 1993; Tona et al., 2001), lo que se suma a la dificultad para remover el excedente de calor, debido a la reducción en la velocidad del aire, producto de un menor espacio entre los huevos (French, 1997).

La mortalidad embrionaria temprana fue menor en el sistema de etapa única debido a la capacidad de la máquina de proveer mayor temperatura al inicio de incubación para un desarrollo apropiado del embrión (Wineland y Oviedo-Rondón, 2009). Brake (2008) reportó que una temperatura de aire de $100.5^{\circ} \mathrm{F}$ para los primeros tres días de incubación estimula la angiogenesis temprana, la utilización 
de la yema y el crecimiento del embrión. En la incubación de etapa múltiple, los embriones no alcanzan $100{ }^{\circ} \mathrm{F}$ hasta que ellos empiezan a producir suficiente calor alrededor de los 8 días de edad, habiendo, por lo tanto, un enfriamiento de los embriones en la primera semana (Boerjan, 2007).

La mortalidad embrionaria temprana fue, por otro lado, menor en los lotes adultos, debido a la mejor calidad de la albúmina y porosidad de la cáscara del huevo (Peebles y Brake, 1987), la cual permite una difusión adecuada de gases, influyendo positivamente en la supervivencia del embrión. La mortalidad embrionaria intermedia no fue afectada por la edad del lote, resultado que concuerda con Almeida et al. (2008), aunque difiere con el estudio de Abudabos (2010), quien encuentra una mayor mortalidad intermedia en huevos provenientes de lotes de madres de mayor edad.

La cantidad de huevos contaminados fue estadísticamente mayor en la incubación de etapa múltiple, lo cual concuerda con el trabajo de Mauldin et al. (2007). Esto se debe a que en las incubadoras de etapa múltiple no es posible realizar una limpieza y desinfección completa, salvo que la unidad se encuentre vacía y en rotación para su limpieza y mantenimiento (Salazar, 2007). En cambio, las incubadoras de etapa única ofrecen la ventaja de poder limpiar y desinfectar las incubadoras cada 18.5 días (Bennett, 2010). Por otro lado, los lotes jóvenes presentaron una menor frecuencia de huevos contaminados, dada la mayor densidad de su cáscara que disminuye el riesgo de penetración de bacterias (Plano, 2005).

En el sistema de etapa múltiple se observó mayor presencia de huevos rajados que en el sistema de etapa única, debido a que en la primera se utilizan bandejas con orificios de menor tamaño, lo que favorece la presentación de microfisuras durante la colocación de los huevos. Asimismo, los lotes de reproductoras de mayor edad presentaron mayor cantidad de huevos rajados debido a que la densidad de la cáscara disminuye conforme aumenta la edad del ave (Brake, 1999).

La frecuencia de huevos picados no nacidos fue más elevada en el lote joven incubado en el sistema de etapa única, pues muchos embriones sobreviven a mortalidades tempranas debido a las mejores condiciones de incubación, pero los pollitos carecen de suficiente fuerza física para romper el cascarón, si se considera el mayor grosor de la cáscara y el menor tamaño del pollito en lotes jóvenes (Pedroso et al., 2005).

La menor tasa de nacimiento total y de primera en el lote de mayor edad incubado en el sistema de etapa múltiple fue debido a una mayor mortalidad embrionaria total (Tona et al., 2001) y a una menor calidad del huevo incubable conforme avanza la edad de las reproductoras (Tona et al., 2004).

El porcentaje de huevos fértiles, como era de esperarse, fue similar en ambos grupos de incubación por ser un factor ajeno al sistema de incubación, ya que está asociado al manejo de las reproductoras en granja. La menor fertilidad en huevos procedentes de reproductoras de mayor edad coincide con otros reportes (Zakaria et al., 2005; Brommer y Rattiste, 2008), debido a una menor actividad sexual y por alteraciones en la calidad del semen. Los cambios en la calidad de semen incluyen una menor motilidad y concentración de espermatozoides, y aumento del número de espermatozoides muertos y anormales (Bramwell et al., 1996).

\section{Conclusiones}

- Se observó una menor mortalidad embrionaria total, y mayor incubabilidad y nacimiento total $(p<0.05)$ en el sistema incubación de etapa única en comparación con el sistema de incubación múltiple. 
- La mortalidad embrionaria total, la incubabilidad y el nacimiento total fue estadísticamente mejor en huevos procedentes de reproductoras adultas, seguido de reproductoras jóvenes y de reproductoras de mayor edad $(\mathrm{p}<0.05)$.

- Se observó interacción significativa entre el sistema de incubación y la edad del lote sobre la mortalidad embrionaria total, la incubabilidad y el nacimiento total $(\mathrm{p}<0.05)$, observándose un mejor comportamiento en la incubación de etapa única en todas las edades. Asimismo, se encontró un mejor aprovechamiento de lotes de reproductoras de mayor edad en la incubación de etapa única.

- La fertilidad estuvo influenciada por la edad del lote $(\mathrm{p}<0.05)$.

\section{Literatura Citada}

1. Abudabos A. 2010. The effect of broiler breeder strain and parent flock age on hatchability and fertile hatchability. Int $\mathbf{J}$ Poultry Sci 9: 231-235.

2. Almeida JG, Vieira SL, Reis RN, Berres J, Barros R, Ferreira AK, Furtado FVF. 2008. Hatching distribution and embryo mortality of eggs laid by broiler breeders of different ages. Rev Bras Cienc Avic 10: 89-96.doi: 10.1590/S1516-635X2008000200003

3. Bennett B. 2010. The advantages of single stage versus multi stage incubation. Int Hatchery Pract 24: 7-9.

4. Boerjan M. 2004. Single stage incubation is the most natural choice. World Poultry 20(7): 18-20.

5. Boerjan M. 2007. Incubación de linajes genéticos modernos de reproductoras pesadas: un nuevo concepto. En: Memorias $\mathrm{XX}$ Congreso Latinoamericano de Avicultura. Brasil. p 317-324.

6. Bongalhardo DC. 2012. Predicting hatching success by testing egg fertility. En: XXIV World's Poultry Congress. Brasil.

7. Brake JT. 1999. Análisis de riesgo de los puntos críticos en el proceso de incubación para producir pollitos bebés de alta calidad. En: Memorias XVI Congreso Latinoamericano de Avicultura. Perú. p 218-228.

8. Brake JT. 2008. A discussion of multistage and single-stage incubation by someone not selling incubators. En: X Congreso Internacional de Avicultura. Maracaibo, Venezuela.

9. Bramwell RK, McDaniel CD, Wilson JL, Howarth B. 1996. Age effect of male and female broiler breeders on sperm penetration of periveitelline layer overlying the germinal disc. Poult Sci 75: 755-762.

10. Brommer JE, Rattiste K. 2008. «Hidden» reproductive conflict between mates in a wild bird population. Evolution 62: 2326-2333. doi: 10.1111/j.15585646.2008.00451.x

11. French NA. 1997. Modeling incubation temperature: the effects of incubator design, embryonic development, and egg size. Poult Sci 76: 124-133.

12. Hemeryck P. 2009. El concepto de biorespuesta. En: Memorias XXI Congreso Latinoamericano de Avicultura. Cuba. p 367-375.

13. Hulet RM. 2007. Managing incubation: where are we and why? Poult Sci 86: 1017-1019.

14. Hulet RM, Gladys G, Hill D, Meijerhof R, El-Shickh T. 2007. Influence of egg shell embryonic incubation temperature and broiler breeder flock age on posthatch growth performance and carcass characteristics. Poult Sci 86: 408-412.

15. Lourens $A$, van den Brand $H$, Heetkamp MJ, Meijerhof R, Kemp B. 2007. Effects of eggshell temperature and oxygen concentration on embryo growth and metabolism during incubation. Poult Sci 86: 2194-2199. doi: 10.1093/ps/ 86.10.2194

16. Mauldin JM, Kuzniak SA, Gardino TL. 2007. Comparisons of hatchability measures in Jamesway Platinum single stage incubators with Jamesway Multistage incubators in broiler hatchery in Georgia. Poult Sci 86: 403-404 (Abstr). 
17. Meijerhof R, van Beek G. 1993. Mathematical modeling of temperature and moisture loss of hatching eggs. $\mathrm{J}$ Theor Biol 165: 27-41.

18. Meijerhof R. 2011. Different breeds demand different incubation measures. World Poultry 27(5): 40-41.

19. Navarro MP. 2003. Puntos críticos de incubación y primera semana de vida en parrilleros de conformación. En: Memorias XVIII Congreso Latinoamericano de Avicultura. Bolivia. p 93-96.

20. Nilipour A. 2009. Efecto de reproductoras, su manejo, incubación y embriogénesis en su progenie. En: Memorias XXI Congreso Latinoamericano de Avicultura. Cuba. p 357-361.

21. Pedroso AA, Andrade MA, Café MB, Leandro NS, Menten JF, Stringhini JH. 2005. Fertility and hatchability of eggs laid in the pullet-to-breeder transition period and in the initial production period. Anim Reprod Sci 90: 355364.doi:10.1016/j.anireprosci.2005.03.001

22. Peebles ED, Brake J. 1987. Eggshell quality and hatchability in broiler breeder eggs. Poultry Sci 66: 596-604.

23. Plano CM, Di Matteo AM. 2001. Atlas de patología de la incubación del po1lo. $2^{\mathrm{a}}$ ed. Buenos Aires: Granja Tres arroyos. $119 \mathrm{p}$.
24. Plano CM. 2005. Embriodiagnóstico como herramienta de trabajo. Avicultura Prof 23(1): 23-27.

25. Salazar A. 2007. Incubación: opciones operativas. Ind Avícola 54(2): 25-29.

26. Tona K, Bamelis F, Coucke W, Bruggeman V, Decuypere E. 2001. Relationship between broiler breeder's age and egg weight loss and embryonic mortality during incubation in large-scale conditions. J Appl Poult Res 10: 221-227.

27. Tona K, Onagbesan O, De Ketelaere B, Decuypere E, Bruggeman E. 2004. Effects of age of broiler breeders and egg storage on egg quality, hatchability, chick quality, chick weight, and chick posthatch growth to forty-two days. J Appl Poultry Res 13: 10-18.

28. Wineland M, Oviedo-Rondón E. 2009. Manejo del desarrollo embrionario para optimizar el desempeño del pollo. Ind Avícola 56(2): 14-16.

29. Zakaria AH, Plumstead PW, Romero-Sanchez $H$, Leksrisompong $N$, Osborne J, Brake J. 2005. Oviposition pattern, egg weight, fertility, and hatchability of young and old broiler breeders. Poult Sci 84: 1505-1509. doi: $10.1093 / \mathrm{ps} / 84.9 .1505$ 